\title{
EDITORIAL
}

\section{LOW SOCIOECONOMIC STATUS AND UNHEALTHY LIFESTYLE LEAD TO HIGH MORBIDITY IN YOUNG ROMA OF EAST SLOVAKIA}

Roma people constitute one of the oldest and largest minorities in Europe. In Slovakia, there are approximately 400,000 Roma, and represent $7.5 \%$ of total population (1). However, according to recent official census in 2010, only 105,738 (2\% of total population) citizens declared themselves as Roma ethnic. Approximately one sixth of Roma people live in segregated settlements (1). This supplement contains results of the HepaMeta study, which has aimed to map the socioeconomic, lifestyle, selected anthropometric, and health-related aspects of young Roma people living in the settlements and their majority counterparts. This study was conducted in 2011 and its main goal was to explore the prevalence of hepatitis B and C and metabolic syndrome. A group of 452 Roma aged 18-55 years, living in settlements (mean age $=34.7 ; 35.2 \%$ men) was compared to a control group of 403 non-Roma randomly chosen (mean age $=33.5 ; 45.9 \%$ men) from the patient database of collaborating general practitioners. Data were obtained by questionnaire, anthropometric measures and analysed blood and urine samples (2).

Roma population from segregated settlements live in significantly worse socioeconomic conditions compared to the majority, they have significantly worse education and higher unemployment rate. More than $80 \%$ of Roma have only basal education, higher education was attained by only $2.3 \%$ of this group compared to the majority population in which almost $80 \%$ completed higher education. More than $90 \%$ of Roma people are unemployed. Unemployment rate in the majority population in the studied East Slovakia region is approximately $25 \%$. Two thirds of Roma people, but only $7.2 \%$ of the majority population receive social allowances. Approximately two thirds of Roma and one in 25 persons of the majority population cannot pay collection orders and current expenditures. Significant differences have been also found in the standard of living. Just half of Roma people have a stable water supply, toilet, bathroom or shower, whereas in the majority these utilities are available up to 95\% of persons. One sixth of Roma people have no electricity (3). Significant differences were also demonstrated in the lifestyle of these groups. Roma men and women have less physical activity (sports, dance, walking) compared to the majority. On the other hand, higher physical activity associated with household was documented in Roma women, which is probably associated with higher number of children in Roma families. Roma people smoke cigarettes more often and are heavy smokers compared to the majority population. Alcohol use among Roma men was comparable to non-Roma men, but Roma women reported lower use of alcohol compared to the majority (4). People from segregated Roma settlements also reported unhealthy diet. They reported eating less fruits, vegetables and dairy products. Roma women reported higher consumption of meat and soft drinks. These differences in eating habits could be associated with higher prevalence of metabolic syndrome in younger age (5).

Several significant anthropometric differences were found. Roma men were on average $8.5 \mathrm{~cm}$ and women $9.5 \mathrm{~cm}$ less tall than their counterparts from the majority population. Prevalence of obesity was comparable between Roma and non-Roma men, but Roma women were significantly more obese than women from the majority population. Mean waist circumference was similar between Roma and non-Roma men, but Roma women, despite being less tall, had on average $6.5 \mathrm{~cm}$ bigger waist circumference compared to women from the majority population. Both systolic and diastolic blood pressures were comparable between Roma and the majority group, but it is necessary to take into account that predominantly young participants were evaluated (6).

Pivotal part of the HepaMeta study was to assess the health status in Roma population living in segregated settlements and their counterparts from the majority population. Young Roma people more often assessed their own health as bad compared to the majority (40.7\% vs. $17.1 \%)$. Several causes of this disbalance were explored by the authors. Poverty was reported as the main barrier in accessing healthcare by almost $50 \%$ of Roma people, compared to only $5 \%$ of the majority population. Other significant barriers were bad traffic connection, problems with orientation, lack of trust in healthcare personnel, fear or bad experience, no possibility of babysitting, and own curative methods (7).

Increased hepatitis B prevalence in segregated communities was first described by Spanish authors 20 years ago (8). The HepaMeta study documented very high prevalence of chronic hepatitis B virus infection $-12.5 \%$. This prevalence was approximately the same as in Asian countries. More than half of studied Roma population had come in contact with hepatitis B during their lives (9). On the other hand, hepatitis C prevalence among Roma population was less than 1\%, approximately the same level of prevalence as had been found out by analysis of available epidemiological data from Slovakia obtained several years ago (9, 10). High prevalence of hepatitis B could be caused by various factors. Most important is vertical transmission from mother to the child during childbirth. Previous studies have documented three times higher prevalence of HBsAg positivity among pregnant women in districts with more than $5 \%$ of Roma inhabitants, compared to districts with less than 5\% of Roma inhabitants (11).

Hepatitis B is transmitted by sexual intercourse to a greater extent than hepatitis C. Therefore, sexual behaviour of the Roma population in settlements could be an important factor for hepatitis B infection. Other identified risk factors were male-to-male sex, higher age, tattoo, and past imprisonment (9). Important data about hepatitis B and metabolic syndrome are presented. Although the risk of hepatitis B infection was approximately the same between metabolic syndrome positive and negative groups, hepatitis B patients with metabolic syndrome had significantly higher levels of HBV DNA. Furthermore, total cholesterol and apolipoprotein B100 had a significant quadratic relationship with HBV DNA. On the other hand, patients with hepatitis B had lower levels of total cholesterol, LDL cholesterol and apoliporotein B100 than patients without hepatitis B $(12,13)$. Chronic hepatitis B could be often asymptomatic and could progress to liver cirrhosis. Hepatocellular carcinoma is another major complication and could appear in 
asymptomatic chronic hepatitis as well as in liver cirrhosis. These diseases have very high mortality and their treatment is economically demanding as well (14). Vaccination against hepatitis B has been known since 1971, but in Slovakia it has been routinely applied in newborns only since $1998(15,16)$. Vaccination generally significantly reduces incidence and prevalence of hepatitis B and its complications (liver cirrhosis and hepatocellular carcinoma). Authors have included participants who were not routinely vaccinated against hepatitis B. In view of very high reported prevalence of hepatitis B in Roma population in segregated settlements, routine vaccination of Roma people without serological markers of hepatitis B should be considered.

Metabolic syndrome was diagnosed in $29.2 \%$ of Roma population, but only in $20.7 \%$ of the majority population (17). Dyslipidemia with decreased levels of HDL cholesterol was also more prevalent in the Roma population compared to the majority (18). Obese Roma people had larger waist circumference, hip circumference, waist to hip ratio, lower levels of HDL cholesterol, adiponectin, and higher levels of triacylglyceroles. Furthermore, inflammatory parameters (CRP and TNF alpha) were elevated in this population (19). Prevalence of metabolic syndrome increases with age. In the study population men and women aged 40 and above had multiple times higher risk of metabolic syndrome compared to the age group 18-39 years. In the Roma population metabolic syndrome significantly increases cardiovascular risk (20). Severe complications of coronary heart disease were detected in Roma population at significantly younger age compared to the majority population. Roma people who had undergone coronarography were on average 5 years younger than the majority population (52 vs. 57). They suffered from significant coronary stenosis and multiple stenosis requiring bypass surgery as well as from myocardial infarction more frequently than members of the majority population (60\% vs. $44 \%)$. This is in line with the reported data on more frequent and more severe metabolic syndrome as well as reduced statins use compared to the majority population (21).

Patients with metabolic syndrome have increased risk not only of coronary heart disease, but non-alcoholic fatty liver disease as well. Authors report that Roma people (abstaining from alcohol) with elevated activity of serum gamma-glutamyl transpeptidase (GGT) had significantly more often metabolic syndrome, but also more often fulfilled individual criteria of metabolic syndrome with the exception of decreased HDL cholesterol. In these patients authors also report elevated levels of inflammatory proteins (ferritin and hs-CRP) compared to Roma people with normal levels of GGT. Nonalcoholic fatty liver disease is another disease that was found to be very prevalent in Roma population, and these patients have increased risk of liver and cardiovascular morbidity (22).

Besides hepatitis B, other sexually transmitted diseases could be expected in Roma population. Results from the presented HepaMeta study report showed trend towards higher prevalence of Chlamydia trachomatis infection in the Roma population compared to the age adjusted majority population (23). In the view of previously presented data on barriers in accessing healthcare and on socioeconomic conditions and lifestyle among the Roma population in settlements, higher prevalence of other diseases could be expected. Authors report higher prevalence of kidney diseases in Roma women compared to the majority. In fact, all 6 young persons with significant proteinuria were Roma women. Roma women compared to the age adjusted majority women group had significantly lower glomerular filtration rate. In total, Roma women had 56\% higher risk of chronic kidney diseases than their majority counterparts (24). Authors also describe more frequent proteinuria associated with elevated levels of total cholesterol in Roma men and women in settlements, compared to the majority (18). Higher prevalence of proteinuria and reduced glomerular filtration rate in younger age predict higher risk of end-stage renal disease later on. Kol'vek et al. found out that Roma people have 2.85 times higher relative risk of developing end-stage renal disease compared to the age adjusted majority. Roma people constitute $11.6 \%$ of dialyzed patients in Slovakia. They are on average 10 years younger and have more often diabetic nephropathy at time of the first hemodialysis compared to the majority population (25).

Authors and contributors of the HepaMeta study have extensively mapped the socioeconomic conditions, lifestyle and morbidity of the younger Roma population living in segregated settlements in the eastern Slovakia. Although poor living conditions and lifestyle, unemployment and poverty were expected, authors report an alarming prevalence of severe diseases, specifically chronic viral hepatitis B, nonalcoholic fatty liver disease, metabolic syndrome, and kidney disease. Therefore, it is not a big surprise that life expectancy of Roma men and Roma women compared to the majority is 7.5 years and 6.6 years lower, respectively (26). Roma minority is a big challenge from the viewpoint of social inclusion and integration policies - as both called for by international organizations and committed to by state authorities. The segregation in the communities creates sense of powerlessness and hopelessness among Roma people on one hand and lot of effort to improve their socioeconomic conditions by competent national and local bodies on the other. Providing adequate education and employment is surely one of the best sustainable ways to reduce poverty and improve the socioeconomic status of Roma people, but vast majority of attempts whether national or international have brought only a little improvement. It is absolutely necessary to put in place such mechanisms and instruments that maximally shorten the way "from intended help to its recipient". It is important to decrease distrust, apathy and reliance on welfare of Roma people in these settlements as well as suspicion, antipathy and discriminatory approaches on the side of majority.

Taking into account the current living conditions of Roma it is advisable to implement some immediate health protection and health care measures that can go beyond the scope of generally provided health benefits. Recalling the outcomes of this study, the vaccination of all Roma people in the settlements against hepatitis B is a priority. It could prevent the chronic hepatitis B and its late stage complications, which will in the long run save a lot of money needed to treat these patients later on. The decreased morbidity and increased life expectancy can be expected after implementing a whole range of interventions including the change of socioeconomic conditions and health awareness of Roma people living in segregated communities. Only through a whole-of-society approach promoting equity in health ensuring access to good quality health services and providing community assistance in care for health it will be possible to get rid of the negative legacy associated with the desperate life of Roma minority in Slovakia.

Darina Sedláková

Head of the WHO Country Office, Slovakia 


\section{REFERENCES}

1. Ministry of the Interior of the Slovak Republic. An atlas of Roma communities [Internet]. Bratislava: Ministry of the Interior of the Slovak Republic; 2013 [cited 2013 Nov 17]. Available from: http://www.minv. sk/?atlas_2013. (In Slovak.)

2. Madarasová Gecková A, Jarčuška P, Mareková M, Pella D, Siegfried L, Jarčuška P, et al.; HepaMeta Team. HepaMeta - Prevalence of hepatitis $\mathrm{B} / \mathrm{C}$ and metabolic syndrome in population living in separated and segregated Roma settlements: a methodology for a cross-sectional populationbased study using community-based approach. Cent Eur J Public Health. 2014 Mar;22 Suppl:S6-11.

3. Madarasová Gecková A, Babinská I, Bobáková D, Dankulincová Veselská Z, Bosáková L, Kolarčik P, et al.; HepaMeta Team. Socioeconomic characteristics of the population living in Roma settlements and their association with health and health-related behaviour. Cent Eur J Public Health. 2014 Mar;22 Suppl:S57-64.

4. Babinská I, Madarasová Gecková A, Jarčuška P, Pella D, Mareková M, Štefková G, et al.; HepaMeta Team. Does the population living in Roma settlements differ in physical activity, smoking and alcohol consumption from the majority population in Slovakia? Cent Eur J Public Health. 2014 Mar;22 Suppl:S22-7.

5. Hijová E, Madarasová Gecková A, Babinská I; HepaMeta Team. Do eating habits of the population living in Roma settlements differ from those of the majority population in Slovakia? Cent Eur J Public Health. 2014 Mar;22 Suppl:S65-8.

6. Babinska I, Dankulincova Veselska Z, Bobakova D, Pella D, Panico S, Reijneveld SA, et al.; HEPA-META team. Is the cardiovascular risk profile of people living in Roma settlements worse in comparison with the majority population in Slovakia? Int J Public Health. 2013 Jun;58(3):417-25.

7. Jarcuska P, Bobakova D, Uhrin J, Bobak L, Babinska I, Kolarcik P, et al.; HEPA-META team. Are barriers in accessing health services in the Roma population associated with worse health status among Roma? Int J Public Health. 2013 Jun;58(3):427-34.

8. Virto Ruiz MT, Marín Alcalá MPL, Pascual Val T, López Morrás C, Aramburu Bergua I, Zubicoa Ventura J. Endemic hepatitis B in 2 marginal ethnic minorities. Comparative study. Med Clin (Barc). 1993 Sep 11;101(7):245-8. (In Spanish.)

9. Veselíny E, Janičko M, Dražilová S, Siegfried L, Pastvová L, Schréter I, et al.; HepaMeta Team. High hepatitis B and low hepatitis C prevalence in Roma population in eastern Slovakia. Cent Eur J Public Health. 2014 Mar;22 Suppl:S51-6.

10. Schréter I, Kristian P, Klement C, Kohútová D, Jarčuška P, Mad'arová L, et al. Prevalence of hepatitis C virus infection in Slovakia. Klin Mikrobiol Infekc Lek. 2007 Apr;13(2):54-8. (In Slovak.)

11. Kristian P, Dankulincová Veselská Z, Paraličová Z, Jarčuška P, Virág L, Valková I, et al. Regional and ethnic aspects of viral hepatitis B among pregnant women. Cent Eur J Public Health. 2013 Mar;21(1):22-5.

12. Janičko M, Senajová G, Dražilová S, Veselíny E, Fedačko J, Siegfried L, et al.; HepaMeta Team. Association between metabolic syndrome and hepatitis B virus infection in the Roma population in eastern Slovakia: a population-based study. Cent Eur J Public Health. 2014 Mar;22 Suppl:S37-42.
13. Jarčuška P, Janičko M, Kružliak P, Novák M, Veselíny E, Fedačko J, et al. Hepatitis B virus infection in patients with metabolic syndrome: A complicated relationship. Results of a population based study. Eur J Intern Med. 2014 Mar;25(3):286-91.

14. Oltman M, Gürtler L, Jarčuška P. Viral hepatitis. In: Duriš I, Hulín I, Bernadič M, editors. Principles of internal medicine. Bratislava: SAP; 2001. p. 1081-111. (In Slovak.)

15. Jarčuška P. History of hepatology in 20th century. Trendy Hepatol. 2009;1(1):4-11. (In Slovak.)

16. Kristian P, Schréter I. Epidemiology of hepatitis B in the world and in Slovakia. Trendy Hepatol. 2009;1(2):4-7. (In Slovak.)

17. Fedačko J, Pella D, Jarčuška P, Siegfried L, Janičko M, Veselíny E, et al.; HepaMeta Team. Clinical and biochemical determinants of metabolic syndrome among Roma and non-Roma subjects in the eastern part of Slovakia. Cent Eur J Public Health. 2014 Mar;22 Suppl:S75-80.

18. Hubková B, Mašlanková J, Stupák M, Guzy J, Kováčová A, Pella D; HepaMeta Team. Assessment of clinical biochemical parameters in Roma minority residing in eastern Slovakia compared with the majority population. Cent Eur J Public Health. 2014 Mar;22 Suppl:S12-7.

19. Petrášová D, Bertková I, Petrášová M, Hijová E, Mareková M, Babinská I, et al.; HepaMeta Team. Biomarkers associated with obesity and overweight in the Roma population residing in eastern Slovakia. Centr Eur J Public Health. 2014 Mar;22 Suppl:S18-21.

20. Fedačko J, Pella D, Jarčuška P, Siegfried L, Janičko M, Veselíny E, et al.; HepaMeta Team. Prevalence of cardiovascular risk factors in relation to metabolic syndrome in the Roma population compared with the non-Roma population in the eastern part of Slovakia. Cent Eur J Public Health. 2014 Mar;22 Suppl:S69-74.

21. Sudzinova A, Nagyova I, Studencan M, Rosenberger J, Skodova Z, Vargova $\mathrm{H}$, et al. Roma coronary heart disease patients have more medical risk factors and greater severity of coronary heart disease than non-Roma. Int J Public Health. 2013 Jun;58(3):409-15.

22. Jarčuška P, Janičko M, Dražilová S, Senajová G, Veselíny E, Fedačko J, et al.; HepaMeta Team. Gamma-glutamyl transpeptidase level associated with metabolic syndrome and proinflammatory parameters in the young Roma population in eastern Slovakia: a population based study. Cent Eur J Public Health. 2014 Mar;22 Suppl:S43-50.

23. Halánová M, Jarčuška P, Kalinová Z, Cáriková K, Oravcová J, Jarčuška P, et al.; HepaMeta Team. The prevalence of Chlamydia trachomatis in the population living in Roma settlements: a comparison with the majority population. Cent Eur J Public Health. 2014 Mar;22 Suppl:S32-6.

24. Rosenberger J, Majerníková M, Jarčuška P, Pella D, Mareková M, Madarasová Gecková A; HepaMeta Team. Higher prevalence of nephropathy in young Roma females compared with non-Roma females. Cent Eur J Public Health. 2014 Mar;22 Suppl:S28-31.

25. Kolvek G, Rosicova K, Rosenberger J, Podracka L, Stewart RE, Nagyova I, et al. End-stage renal disease among Roma and non-Roma: Roma are at risk. Int J Public Health. 2012 Aug;57(4):751-4.

26. Simko V, Ginter E. Short life expectancy and metabolic syndrome in Romanies (gypsies) in Slovakia. Cent Eur J Public Health. 2010 Mar;18(1):16-8. 